\title{
Prescribing for patients on dialysis
}

\section{SUMMARY}

The pharmacokinetics of a drug may be altered in patients with renal impairment who require dialysis. Some drugs are contraindicated.

The drug's clearance and therapeutic index determine if a dose adjustment is needed. A lower dose or less frequent dosing may be required.

Consult a reference source or the patient's nephrologist before prescribing. Start at a low dose and increase gradually. If possible give once-daily drugs after dialysis.

\section{Introduction}

The prevalence of kidney disease is rising and there are now over 11400 Australians receiving dialysis.' These patients may rely on their GPs for much of their medical care. Prescribing for patients who are on dialysis can be challenging, however a few basic principles and the use of easily available reference materials (Box) can ensure that these patients are managed safely. A study in the USA found up to one-third of haemodialysis patients are prescribed a drug at a dose that differs from the recommended dose and adverse reactions occur in one-fifth. ${ }^{2}$ Polypharmacy, multiple comorbid illnesses and drug clearance by dialysis all complicate prescribing. ${ }^{3}$

\section{Dialysis}

Dialysis is the transfer of uraemic solutes from blood to an extracorporeal fluid (dialysate) by diffusion across a semi-permeable membrane. This may be done by pumping blood through a dialyser containing a membrane and dialysate (haemodialysis), or by instilling dialysate into the peritoneal cavity and using the peritoneum itself as a membrane (peritoneal dialysis). Solute removal via haemodialysis is relatively efficient and so can be done intermittently - typically three times per week - whereas peritoneal dialysis is less efficient and so is usually required for 12-24 hours every day.

\section{Principles of prescribing}

Renal impairment reduces the clearance of some drugs. ${ }^{4}$ When prescribing for patients on dialysis, it is essential to consult a reference guide (Box) to determine if the drug is subject to renal clearance and requires a dose adjustment. Given the paucity of large pharmacokinetic studies, dosing recommendations often differ and it may be difficult to favour one source over another. If no 'dialysis' dose is available, one should assume that the patient's glomerular filtration rate is less than $10 \mathrm{~mL} / \mathrm{min} / 1.73 \mathrm{~m}^{2}$. Although many patients have some residual renal function, their serum creatinine may fluctuate markedly and it should not be used to estimate glomerular filtration rate.

Dose adjustments can be made by reducing the dose, increasing the interval between doses or a combination of the two. The approach to take is determined by the relative importance of stable serum drug concentrations (for instance to maintain the antimicrobial effect of penicillins), the adverse effects of peak concentrations after intermittent doses, and patient convenience.

Multiple practitioners often share the care of patients on dialysis (e.g. GPs, specialist physicians, vascular surgeons and dialysis nurses). Information about the adjusted dosing regimen should be included in correspondence and, where appropriate, explain why the dose has been adjusted, to avoid confusion.

\section{Pharmacokinetics}

The two main considerations that determine if a particular drug requires dose reduction in dialysis patients are renal clearance and therapeutic index. Other factors that may affect dosing include clearance by dialysis, increased availability of highly proteinbound drugs due to hypoalbuminaemia, ${ }^{5}$ altered volume of distribution and the presence of comorbid hepatic dysfunction.

\section{Brendan Smyth \\ Renal registrar}

Ceridwen Jones

Senior clinical pharmacist

\section{John Saunders}

Consultant nephrologist

Royal Prince Alfred Hospital Sydney

\section{Key words}

haemodialysis, kidney, pharmacokinetics, renal disease

Aust Prescr 2016;39:21-4 http://dx.doi.org/10.18773/ austprescr.2016.008

\section{Box Suggested resources for drug dosing in dialysis}

\author{
Australian Medicines Handbook (https://amhonline.amh.net.au) \\ Therapeutic Guidelines: Antibiotic. Version 15 (www.tg.org.au) \\ MIMS Australia (http://mims.com.au) \\ Bailie and Mason's 2014 Dialysis of Drugs (http://renalpharmacyconsultants.com/ \\ publications) \\ Oxford Handbook of Dialysis. 3rd ed. Oxford: Oxford University Press; 2009. \\ The Renal Drug Handbook. 4th ed. London: Radcliffe Publishing; 2014.
}




\section{Clearance}

Consider the magnitude of the renal component of total clearance of the drug and any active metabolites. For drugs subject to significant renal clearance, the marked decrease in glomerular filtration rate seen in patients on dialysis results in an increase in half-life ${ }^{6}$ and drug accumulation with repeated dosing in the absence of dose adjustment. These changes also apply to renally cleared drug metabolites which may be active or toxic.

The increased half-life also prolongs the time to achieve a steady-state which, in clinical practice, means a longer period is required before judging that the maximum effect of a particular dose has been achieved. ${ }^{7}$ The starting dose should be low and caution is required before increasing drug doses. Given the longer time to steady state, a loading dose can be considered if giving a renally adjusted dose could lead to a delay in reaching a therapeutic serum concentration (for instance, if treating a severe infection). In practice, loading doses are rarely used.

\section{Therapeutic index}

A drug with a wide therapeutic index may be safely given without a dose reduction knowing that, although the drug concentration will be higher, this is unlikely to result in harm. However, drugs with narrow therapeutic indices may require substantial dose reductions. ${ }^{7}$

\section{Dialysis and drug clearance}

Patients on dialysis are subject to extracorporeal clearance of small molecules, including many drugs. The extent to which dialysis removes a particular drug from plasma is dependent on its water solubility, molecular weight, protein binding and volume of distribution. ${ }^{3}$ Many reference sources contain lists of drugs cleared by dialysis (Box).

Haemodialysis can pose a challenge as it is intermittent and has the potential for relatively rapid drug clearance. In practice this is most important when prescribing once-daily drugs, especially antibiotics. It may be best to give them after dialysis. Dose timing is typically left unchanged for drugs dosed more frequently, as complex dosing regimens may reduce adherence to therapy. In peritoneal dialysis, timing is not important as the clearance of small molecules is slower and more even than in haemodialysis. ${ }^{\text {? }}$

\section{Commonly prescribed drugs}

Many drugs are not renally cleared. Specific examples of commonly used drugs include proton pump inhibitors, statins, corticosteroids and calcium channel blockers. They are unlikely to need a dose adjustment in patients on dialysis.

\section{Analgesics}

Patients on dialysis may have comorbid pain, but its treatment is often suboptimal. ${ }^{8,9}$ Paracetamol is the preferred simple analgesic. It is safe and can be used without dose modification. ${ }^{10}$

Although nephrotoxicity might be considered of little importance, non-steroidal anti-inflammatory drugs (NSAIDs) should be avoided as they may cause sodium retention, hypertension and gastrointestinal toxicity. Due to the increased risk of myocardial infarction seen in the general population, we do not recommend cyclo-oxygenase-2 inhibitors in dialysis patients as they are already at markedly higher baseline cardiovascular risk. ${ }^{11,12}$ Topical NSAIDs appear to be safe as systemic absorption is minimal.?

Many opioids, or their active metabolites, are renally cleared (Table). ${ }^{7,10,13,14}$ Codeine and morphine have active, renally excreted metabolites so they are not recommended because of the increased risk of toxicity. Hydromorphone is our preferred oral opioid for treating severe pain. It is five to seven times more potent than morphine so starting doses are correspondingly low (0.5-1 mg orally 6 -hourly). ${ }^{10}$ Its active metabolite hydromorphone-3-glucuronide can accumulate, but is substantially cleared by haemodialysis and is less likely to cause adverse effects than morphine metabolites..$^{15}$ Oxycodone may be used, although the sustained-release formulations should be used only with caution due to the risk of accumulation and toxicity. Fentanyl and buprenorphine both undergo hepatic clearance and can be used when the oral route is not suitable. ${ }^{13}$ Whichever opioid is chosen, it is important to use small starting doses and closely monitor up-titration to avoid toxicity.

Neuropathic pain is common in patients on dialysis. ${ }^{16}$ Amitriptyline is hepatically metabolised and does not accumulate. However, it has numerous adverse effects including anticholinergic effects and postural hypotension which may limit its use in patients with multiple comorbidities. ${ }^{10}$ Gabapentin and pregabalin are effective and may also treat uraemic pruritis. However, they are extensively renally cleared and marked dose reductions are necessary to avoid sedation, ataxia and dizziness. Doses should be taken after dialysis. 10,17

\section{Opioid-induced constipation}

In surveys, over half of the patients on dialysis report constipation. ${ }^{9}$ Prevention of opioid-induced constipation is particularly important in patients on peritoneal dialysis as constipation may markedly reduce its effectiveness. Lactulose, docusate, senna and bisacodyl are all suitable treatments. Preparations containing polyethylene glycol (macrogol) are also generally safe as laxatives or bowel preparation. Patients should be advised that the co-administered 
Table Analgesic use in dialysis ${ }^{6,9-11}$

\begin{tabular}{|c|c|c|c|}
\hline Drug & Clearance & Suggested starting dose & Comments \\
\hline Hydromorphone & $\begin{array}{l}\text { Its major renally excreted metabolite } \\
\text { hydromorphone-3-glucuronide is inactive }\end{array}$ & $\begin{array}{l}0.5-1 \text { mg orally } \\
4 \text { times a day }\end{array}$ & Preferred oral opioid in dialysis patients \\
\hline Oxycodone & $\begin{array}{l}\text { Both oxycodone and its active metabolite } \\
\text { oxymorphone are renally excreted }\end{array}$ & $\begin{array}{l}2.5-5 \text { mg orally } \\
3 \text { times a day }\end{array}$ & $\begin{array}{l}\text { Use controlled-release preparations with } \\
\text { caution }\end{array}$ \\
\hline Tramadol & $\begin{array}{l}\text { Active renally excreted metabolite } \\
\text { O-desmethyltramadol }\end{array}$ & $\begin{array}{l}50 \text { mg orally } \\
\text { twice a day }\end{array}$ & $\begin{array}{l}\text { Maximum } 100 \text { mg twice a day } \\
\text { Avoid controlled-release preparations }\end{array}$ \\
\hline Buprenorphine & $\begin{array}{l}\text { Hepatic metabolism with no accumulation } \\
\text { of metabolites }\end{array}$ & $\begin{array}{l}5 \text { microgram/hour } \\
\text { transdermally }\end{array}$ & Not dialysed \\
\hline Fentanyl & $\begin{array}{l}\text { Hepatic metabolism with no active } \\
\text { metabolites }\end{array}$ & $\begin{array}{l}12 \text { microgram/hour } \\
\text { transdermally }\end{array}$ & $\begin{array}{l}\text { Not dialysed } \\
\text { Use with caution in opioid-naïve patients }\end{array}$ \\
\hline Gabapentin & Renal excretion & $\begin{array}{l}100 \text { mg orally at night } \\
\text { on dialysis days }\end{array}$ & $\begin{array}{l}\text { Large dose reductions required } \\
\text { Can treat uraemic pruritis and restless } \\
\text { legs syndrome }\end{array}$ \\
\hline Pregabalin & Renal excretion & $\begin{array}{l}25 \text { mg orally at night } \\
\text { on dialysis days }\end{array}$ & $\begin{array}{l}\text { Large dose reductions required } \\
\text { Can treat uraemic pruritis and restless } \\
\text { legs syndrome }\end{array}$ \\
\hline Morphine & $\begin{array}{l}\text { Metabolised to renally excreted glucuronide } \\
\text { metabolites (M-6-G and } M-3-G) \\
\text { M-6-G is active and accumulates within } \\
\text { the central nervous system, } M-3-G \\
\text { lacks analgesic activity but may cause } \\
\text { hyperalgesia and allodynia }\end{array}$ & $\begin{array}{l}2.5 \text { mg orally } \\
3 \text { times a day }\end{array}$ & $\begin{array}{l}\text { Avoid if possible } \\
\text { Could be used for emergency analgesia } \\
\text { if hydromorphone or fentanyl not } \\
\text { immediately available }\end{array}$ \\
\hline Codeine & Renally excreted active metabolites & - & Avoid \\
\hline Dextro-propoxyphene & $\begin{array}{l}\text { Cardiotoxic metabolite norpropoxyphene } \\
\text { accumulates }\end{array}$ & - & Avoid \\
\hline Paracetamol & Hepatic clearance & $1 \mathrm{~g}$ orally $3-4$ times a day & Preferred simple analgesic \\
\hline
\end{tabular}

fluid is not significantly absorbed and so does not count towards a fluid restriction. Saline laxatives (containing magnesium or phosphate salts) are contraindicated in patients on dialysis due to the possibility of severe electrolyte disturbances..$^{18}$ In particular, sodium phosphate-containing bowel preparations (Fleet) can cause severe hyperphosphataemia and calcium phosphate deposition. ${ }^{19}$

\section{Antimicrobials}

Many antibiotics require dose adjustment in patients receiving dialysis. Therapeutic Guidelines: Antibiotic provides a comprehensive and user-friendly reference. ${ }^{20}$ Quinolones, sulfamethoxazole with trimethoprim, glycopeptides and aminoglycosides all require significant dose reductions. Trimethoprim should be avoided in patients due to the risk of hyperkalaemia and bone marrow suppression. ${ }^{20,21}$ Nitrofurantoin is primarily renally excreted, and relies on urinary concentration to achieve its effect. It is rarely associated with neurotoxicity and life-threatening pulmonary toxicity. ${ }^{22}$ Despite recent support for extending its use in chronic kidney disease, it should be avoided in patients on dialysis. ${ }^{23}$ Cephalosporins and penicillins have wider therapeutic indices and vary in the need for dose adjustment.7 Once-daily doses should be prescribed after haemodialysis.

The antiviral drug aciclovir and its prodrugs, famciclovir and valaciclovir, are extensively renally excreted. These drugs accumulate rapidly in patients on dialysis and may cause severe neurological toxicity. ${ }^{24}$ They should only be prescribed after discussion with the treating nephrologist and with appropriate dose reduction and close clinical follow-up.

\section{Anticoagulants}

Despite controversy surrounding its use for stroke prevention in dialysis patients with atrial fibrillation, warfarin remains the anticoagulant of choice for those with venous thromboembolism or other indications for anticoagulation. The dose is adjusted according to the INR in the usual manner. Close monitoring and avoidance of supratherapeutic INRs is particularly 


\section{SELF-TEST} QUESTIONS

\section{True or false?}

7. Trimethoprim is not recommended in patients who require dialysis.

8. The usual dose of paracetamol should be reduced by half in patients receiving dialysis.

Answers on page 27 important as patients on dialysis have increased rates of bleeding with warfarin. ${ }^{25}$ Low-molecular-weight heparins are renally excreted and they are rarely used for anticoagulation as their effect is difficult to predict. ${ }^{7}$ Unfractionated heparin is preferred for acute treatment of venous thromboembolism in patients on dialysis.

The newer oral anticoagulants (such as dabigatran and rivaroxaban) are contraindicated. They all undergo a degree of renal clearance which makes them unsuitable for patients on dialysis. ${ }^{26}$

\section{Drugs for diabetes}

Patients with diabetes who need dialysis have reduced insulin clearance, so they may be more liable to hypoglycaemia with both insulin and insulin secretagogues (sulfonylureas). These patients may also be at increased risk of hypoglycaemia unawareness due to comorbid illnesses and co-prescribed drugs. ${ }^{7}$ Gliclazide and glipizide are the preferred sulfonylureas as they have short half-lives and no active metabolites. All sulfonylureas should be started at low doses and up-titrated carefully. The dipeptidyl peptidase-4 inhibitors vary in their suitability for use in dialysis so the product information should be reviewed before prescribing. ${ }^{27}$ Metformin is contraindicated due to the risk of lactic acidosis. Although not renally excreted, thiazolidinediones are associated with fluid retention and are not recommended. ${ }^{7}$ The sodium-glucose co-transporter inhibitors are contraindicated in dialysis patients as they depend on the glomerular filtration of glucose for their effect. ${ }^{28}$

\section{Conclusion}

Recognising that patients on dialysis are more prone to drug toxicity is the first step in avoiding harm. There are many easily accessible reference sources to guide dose adjustments in renal failure. Clinical judgement is always required to balance the required treatment intensity against the risk of toxicity in an individual patient. If in doubt, contact the treating nephrologist or renal unit pharmacist for advice. In general, commence with a low dose, observe closely for adverse effects and increase the dose only after a timely interval. Put simply: 'start low and go slow'. $<$

\section{Conflict of interest: none declared}

\section{REFERENCES}

1. Clayton P, McDonald S, Hurst K, editors. ANZDATA Registry Annual Report 2013. Adelaide: Australia and New Zealand Dialysis and Transplant Registry; 2013. www.anzdata.org.au/anzdata/AnzdataReport/36thReport/ANZDATA_36th_ Annual\%20_Report.pdf [cited 2016 Jan 4]

2. Manley HJ, Drayer DK, Muther RS. Medication-related problem type and appearance rate in ambulatory hemodialysis patients. BMC Nephrol 2003;4:10 http://dx.doi.org/10.1186/1471-2369-4-10

3. Weir MR, Fink JC. Safety of medical therapy in patients with chronic kidney disease and end-stage renal disease. Curr Opin Nephrol Hypertens 2014;23:306-13. http://dx.doi.org/10.1097/01.mnh.0000444912.40418.45

4. Faull R, Lee L. Prescribing in renal disease. Aust Prescr 2007:30:17-20.

5. Meijers BK, Bammens B, Verbeke K, Evenepoel P. A review of albumin binding in CKD. Am J Kidney Dis 2008;51:839-50. http://dx.doi.org/10.1053/j.ajkd.2007.12.035

6. Katzung BG, Masters SB, Trevor AJ. Basic \& clinical pharmacology. LANGE Basic Science. 12th ed. McGraw-Hill Education; 2012.

7. Floege J, Johnson RJ, Feehally J. Comprehensive clinical nephrology. 4th ed. St Louis (MI): Elsevier; 2010.

8. Bailie GR, Mason NA, Bragg-Gresham JL, Gillespie BW, Young EW. Analgesic prescription patterns among hemodialysis patients in the DOPPS: potential for underprescription. Kidney Int 2004:65:2419-25. http://dx.doi.org/10.1111/ j.1523-1755.2004.00658.x

9. Murtagh FE, Addington-Hall J, Higginson IJ. The prevalence of symptoms in end-stage renal disease: a systematic review. Adv Chronic Kidney Dis 2007:14:82-99. http://dx.doi.org/10.1053/j.ackd.2006.10.001

10. Davison SN, Ferro CJ. Management of pain in chronic kidney disease. Prog Palliat Care 2009;17:186-95. http://dx.doi.org/10.1179/ 096992609X12455871937189

11. Andersohn F, Suissa S, Garbe E. Use of first- and second-generation cyclooxygenase-2-selective nonsteroidal antiinflammatory drugs and risk of acute myocardial infarction. Circulation 2006;113:1950-7. http://dx.doi.org/ 10.1161/CIRCULATIONAHA.105.602425

12. Cass A, Chadban S, Gallagher M, Howard K, Jones A, McDonald S, et al. Economic impact of end-stage kidney disease in Australia: Projections to 2020. Melbourne: Kidney Health Australia; 2010.

13. Dean M. Opioids in renal failure and dialysis patients. J Pain Symptom Manage 2004;28:497-504. http://dx.doi.org/10.1016/j.jpainsymman.2004.02.021

14. Filitz J, Griessinger N, Sittl R, Likar R, Schüttler J, Koppert W. Effects of intermittent hemodialysis on buprenorphine and norbuprenorphine plasma concentrations in chronic pain patients treated with transdermal buprenorphine. Eur J Pain 2006;10:743-8. http://dx.doi.org/10.1016/j.ejpain.2005.12.001

15. Davison SN, Mayo PR. Pain management in chronic kidney disease: the pharmacokinetics and pharmacodynamics of hydromorphone and hydromorphone-3-glucuronide in hemodialysis patients. J Opioid Manag 2008;4:335-6.
16. Mambelli E, Barrella M, Facchini MG, Mancini E, Sicuso C, Bainotti S, et al. The prevalence of peripheral neuropathy in hemodialysis patients. Clin Nephrol 2012;77:468-75. http://dx.doi.org/10.5414/CN107188

17. Solak Y, Biyik Z, Atalay H, Gaipov A, Guney F, Turk S, et al. Pregabalin versus gabapentin in the treatment of neuropathic pruritus in maintenance haemodialysis patients: a prospective, crossover study. Nephrology (Carlton) 2012;17:710-7. http://dx.doi.org/10.1111/j.1440-1797.2012.01655.x

18. Murtagh FE, Weisbord S. Symptoms in renal disease; their epidemiology, assessment and management. In: Chambers EJ, Brown EA, Germain M, editors. Supportive care for the renal patient. 2nd ed. Oxford: Oxford University Press; 2010.

19. Heher EC, Thier SO, Rennke H, Humphreys BD. Adverse renal and metabolic effects associated with oral sodium phosphate bowel preparation. Clin J Am Soc Nephrol 2008;3:1494-503. http://dx.doi.org/10.2215/ CJN.02040408

20. Antibiotic. Version 15. In: eTG complete [Internet]. Melbourne: Therapeutic Guidelines Limited; 2014. http://www.tg.org.au/index.php?sectionid=71 [cited 2016 Jan 4]

21. Australian Medicines Handbook. Adelaide: Australian Medicines Handbook Pty Ltd; 2015.

22. Geerts AF, Eppenga WL, Heerdink R, Derijks HJ, Wensing MJ, Egberts TC, et al. Ineffectiveness and adverse events of nitrofurantoin in women with urinary tract infection and renal impairment in primary care. Eur J Clin Pharmacol 2013;69:1701-7. http://dx.doi.org/10.1007/s00228-013-1520-x

23. Singh N, Gandhi S, McArthur E, Moist L, Jain AK, Liu AR, et al. Kidney function and the use of nitrofurantoin to treat urinary tract infections in older women. CMAJ 2015;187:648-56. http://dx.doi.org/10.1503/cmaj.150067

24. Strumia S, De Mitri P, Bionda E. Neurotoxicity of acyclovir and valacyclovir in a hemodialyzed patient. Eur J Neurol 2004;11:68-9. http://dx.doi.org/10.1046/ j.1351-5101.2003.00719.x

25. Genovesi S, Rossi E, Gallieni M, Stella A, Badiali F, Conte F, et al. Warfarin use, mortality, bleeding and stroke in haemodialysis patients with atrial fibrillation. Nephrol Dial Transplant 2015;30:491-8. http://dx.doi.org/10.1093/ndt/gfu334

26. Tran H, Joseph J, Young L, McRae S, Curnow J, Nandurkar H, et al.; Australasian Society of Thrombosis and Haemostasis. New oral anticoagulants: a practical guide on prescription, laboratory testing and peri-procedural/bleeding management. Intern Med J 2014;44:525-36. http://dx.doi.org/10.1111/imj.12448

27. Flynn C, Bakris GL. Noninsulin glucose-lowering agents for the treatment of patients on dialysis. Nat Rev Nephrol 2013;9:147-53. http://dx.doi.org/10.1038/ nrneph.2013.12

28. Moses RG, Colagiuri S, Pollock C. SGLT2 inhibitors: New medicines for addressing unmet needs in type 2 diabetes. Australas Med J 2014;7:405-15. http://dx.doi.org/10.4066/AMJ.2014.2181 